\title{
HEAT-RESISTANT COMPOSITE COATING WITH A FLUIDIZED BED OF THE UNDER-REACTOR MELT TRAP OF A LIGHT-WATER NUCLEAR REACTOR
}

\author{
Bekmuldin M.K. ${ }^{1,3}$, Skakov M.K. ${ }^{1}$, Baklanov V.V. ${ }^{1}$, Gradoboyev A.V. ${ }^{2}$, Akaev A.S. ${ }^{1}$ \\ ${ }^{1}$ Institute of Atomic Energy, Kurchatov, Kazakhstan, Bekmuldin@nnc.kz \\ ${ }^{2}$ National Research Tomsk Polytechnic University, Tomsk, Russia \\ ${ }^{3}$ Shakarim State University, Semey, Kazakhstan
}

\begin{abstract}
The paper is devoted to the analysis of existing options of under-reactor melt traps, designs and disadvantages of these traps. A variation of its own under-reactor melt trap with a heat-resistant composite coating with a fluidized bed is proposed. The description of facility for experimental studies of the heat-resistant composite coating with the fluidized bed is presented. The results of a thermal calculation of the variation of the under-reactor trap with fluidized bed melt are presented. Thermal calculations showed that an increase in the average temperature of the melt is less intense in the model of an under-reactor trap with a fluidized bed, due to heat removal from the corium to the metal to complete the phase transition.
\end{abstract}

Keywords: severe accident, under-reactor melt trap, corium, heat-resistant composite coating, LAVA-B facility

\section{Introduction}

As it is known, currently, thirty-one countries in the world receive energy from nuclear power plants. Kazakhstan is also considering the possibility of building the III + reactor. In this regard, improving the NPP safety is one of the urgent and priority tasks. After several major accidents, the entire world community is solving this problem. The experience of NPP operation has shown that there is a possibility of a severe accident developing even with a sufficiently low probability. There are many scenarios for a severe accident development, one of which is the interaction between reactor core melt (corium - molten core material, which forms, according to their chemical composition and oxidation conditions, a system of two immiscible liquids - oxide and metal [1]) and the vessel, with its further penetration and leakage into under-reactor melt trap. The under-reactor melt trap provides receiving, placement and cooling of the corium. Increased safety is achieved by eliminating the release of liquid and solid radioactive materials outside the under-reactor melt trap, which ensures the elimination of damage to the hermetic enclosure system for the accident localization area [2].

\section{Analysis of the existing variations of under-reactor melt traps}

At the first stages of the nuclear power development, it was proposed to have a pool at the bottom of the reactor shaft, filled with water, in case of destruction of the nuclear reactor vessel, falling into which the melt would be cooled due to the evaporation of the stored water. The vulnerability of this method of heat removal from corium is hydrogen generation, where there is a probability of a steam explosion [3], parameters of the shock wave of which exceed the safety margin of the containment.

It was proposed[4]to install channels lined with heat-resistant ceramics and equipped with cooling fins on the outside under the NPP foundation. The disadvantage was the complication and weakening of the NPP foundation and the length of such channels: with the required total surface of more than $350-400 \mathrm{~m}^{2}$ and maximum possible diameter of $300 \mathrm{~mm}$, required length would be more than $350-400$ meters. There is an option of the device within the containment with an increased heat removal surface due to a system of longitudinal slots, inside which the fuel melt enters, and a system of cooling pipes is placed in the walls of the slots, where water will be supplied in case of a severe accident. The disadvantage is formation of a large amount of hydrogen, loss of tightness of the slotted cavities for the corium with their filling with water, which will create a risk of steam explosions [4]. 
The main thread in localizing the consequences of a severe accident with core melting of a light-water nuclear reactor is the option with a crucible-type trap(for example, in[5-21], as one of the promising and effective methods of confining and cooling the corium. There are many variations of the dry crucible trap. The main purpose of this type of trap is to localize residual energy release in the corium and prevent it from falling outside the trap. This concept is based on filling the under-reactor space with blocks of cassettes filled with sacrificial material [22], placed in a steel heat exchanger-crucible [23, 24], which in turn is also melted sacrificial material and is surrounded by heat-insulating layers cooled by an annular sectioned pool with boiling water. The main difference between all crucible-type traps lies in the design and composition of the sacrificial material. In [11], the trap is mounted on supports under the reactor vessel and is made in the form of a container with a spherical bottom, which includes a heat-insulating protective layer of zirconium dioxide and an outer layer of stainless steel. The heat-insulating protective layer contains an additional bulk layer made of a mixture of fragments of porous high-temperature ceramics and neutron-absorbing materials.

In work [12], the under-reactor melt trap includes a cooled double-walled casing, the bottom of which is deepened towards the center with a slope, filled with sacrificial material. The material consists of several upper and lower cassettes. The upper and lower cassettes contain ceramic plates made with microchannels, separated by horizontal and vertical slotted channels, and mounted on top of each other.

In [14], the trap consists of a cooled double-walled vessel filled with sacrificial material, a guiding element for organizing the melt movement, and a passive system for supplying water to the melt surface. In this case, the sacrificial material is folded into blocks, each of which is divided into segments by attachment points mounted radially relative to the vertical axis of the device. The segments are filled with sacrificial material with formation of free areas communicating with the central through hole for the passage of the melt, while cooling the vessel is made in the form of a passive system that can function with natural circulation of cooling water for an unlimited time, using water from the volume of the containment and sump tanks. In [19], the under-reactor melt trap is equipped with a cooled shell in the form of a multilayer vessel to protect the outer heat exchange wall from dynamic, thermal and chemical influences, and a sacrificial material for diluting the melt. In this case, a multilayer vessel has metal outer and inner walls and a filler placed between them made of a material that is low-heat-conductive in relation to the walls' materials. In [20], a trap with sacrificial and protective materials was installed in the concrete shaft of the reactor. A room adjoins the concrete shaft with layers of sacrificial, steel and protective materials located on the floor successively from top to bottom. The sacrificial material is made using concrete technology with a minimum water content. The entire room together with the trap is a melt containment system. In addition to the design, there are various options in the composition of trap material, for example, in [21], the melt trap material includes $\mathrm{Al}_{2} \mathrm{O}_{3}, \mathrm{SiO}_{2}$, additionally contains $\mathrm{Fe}_{2} \mathrm{O}_{3}$ and/or $\mathrm{Fe}_{3} \mathrm{O}_{4}$ and a target additive in the form of $\mathrm{Gd}_{2} \mathrm{O}_{3}$, orEu $\mathrm{O}_{2} \mathrm{O}_{3}$, or $\mathrm{Sm}_{2} \mathrm{O}_{3}$.

Thus, the issue of choosing the design and materials of the under-reactor melt trap for efficient localization of residual energy release in corium has limited experience and is still relevant.

\section{Heat-resistant composite coatings with a fluidized bed}

The issue of choosing a trap material is to ensure deep subcriticality of the core melt of a nuclear reactor, its nuclear safety and high efficiency of localization. Fast and reliable localization of the melt requires efficient removal of heat released in the volume of the corium melt. The best coolant for heat removal is water, however, the need to prevent steam explosions and generate large amounts of hydrogen requires additional technical solutions. In this regard, methods of heat removal from the melt, which exclude the direct supply of water to the surface, are becoming relevant. In this connection, an idea arose to install a certain amount of metal at the bottom of the trap, together with the sacrificial material. When corium enters the under-reactor melt trap, heating and further phase transition of the metal will occur, which accordingly requires a significant amount of energy. The advantage of molten metal is the absence of hydrogen formation reactions, as well as a low risk of steam explosion compared to water.

The requirements for the material shall satisfy not only the physical and chemical properties, but also the economic feasibility of using a heat-resistant material:

- efficient heat removal from the corium (comparable to water);

- dilution of corium, and, accordingly, a decrease in the density of energy release from fission products and ensuring the state of nuclear subcriticality of the system; 
- protection of the trap wall from mechanical and/or thermal shock when corium entry;

- reducing the corium density to prevent the effect of focusing heat fluxes on the water-cooled surface of the vessel of the under-reactor melt trap [25];

- use of the material should not significantly lead to an increase in the cost of building future traps.

The work will be devoted to the preparation and implementation of experimental studies of the interaction between corium with heat-resistant composite coatings and a fluidized bed, as well as further development of recommendations on possible use of a heat-resistant fluidized bed coating for a protective lining of the under-reactor melt trap. Experimental studies will allow to carry out a substantiated analysis of efficiency of a heat-resistant fluidized bed coating for a designed under-reactor melt trap intended to increase the safety of a nuclear power plant in the event of a severe accident with reactor core melting. The use of a fluidized bed enables limiting the refractory temperature by the boiling point of the layer facing the corium, and also provides effective heat removal from the corium due to the energy spent on the phase transition of the fluidized bed material into vapor state.

To analyze the heat removal efficiency of residual energy release of the corium by the heat-resistant composite coating, we carried out a thermal calculation in the ANSYS program of the heat-resistant composite coating with and without a fluidized bed, using the finite volume method for solving the problems of fluid flow and heat transfer. The finite volume method is based on dividing the area of interest into a finite set of control volumes. In this case, the equations of conservation of mass, momentum, energy by combining all compound equations into a system of algebraic equations. Due to the symmetry of the traps with respect to the central axis, a two-dimensional axisymmetric computational domain was chosen to simulate heat transfer in melt traps.

Figure 1 shows models of an under-reactor melt trap with a heat-resistant coating with a fluidized bed and without a fluidized bed. In one of the models there is a metal layer. To compare the original model, the melt traps with the trap with a lead layer in each of the calculations are equivalent:

a) initial conditions (corium temperature $2000^{\circ} \mathrm{C}$ );

b) the mass of the heated corium;

c) thermophysical properties of materials;

d) power released in the melt as a result of the presence of residual energy release [26];

e) estimated heating time.

The calculation models take into account the heat transfer by radiation between the surface of the corium, the concrete trap, as well as convective heat transfer between the external surfaces of the model and the environment.
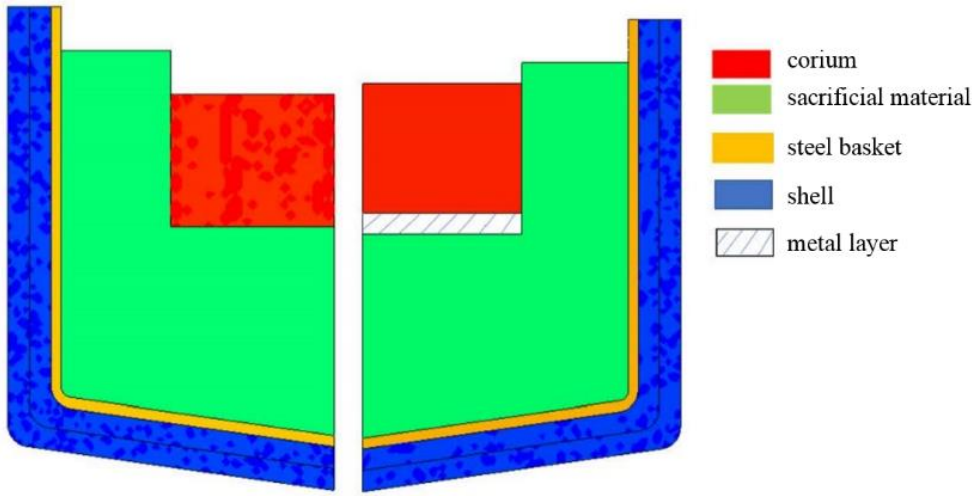

Fig.1. Model of an under-reactor trap without and with a fluidized bed.

As a result of computer modeling of the developed thermophysical model of the interaction of the corium with the elements of the concrete trap, its temperature field was obtained. Figure 2 shows calculated temperature field after interaction between corium and sacrificial materials of the under-reactor melt trap in 150 minutes. It can be seen that temperature field of the under-reactor melt trap with a fluidized bed is lower and more uniformly distributed than temperature field of the under-reactor trap without a fluidized bed.

Changes in average temperature of the melt in under-reactor traps with a composite refractory material without a fluidized bed (model 1) and with a fluidized bed (model 2) are shown in Figure 3.The increase in the average temperature of the melt is caused by residual energy release from the corium. 


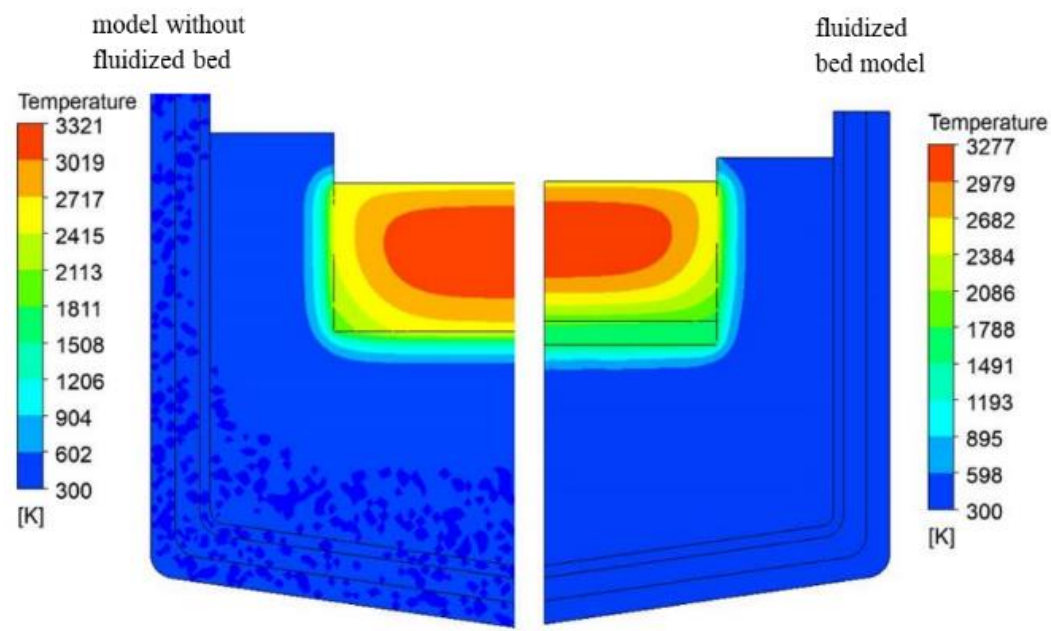

Fig.2. Calculated temperature field of the under-reactor melt trap in 150 minutes after interaction with corium.

As can be seen from Fig. 3, an increase in the average melt temperature is less intense in the model of the under-reactor trap with a fluidized bed, due to heat removal from the corium to the metal for the phase transition.

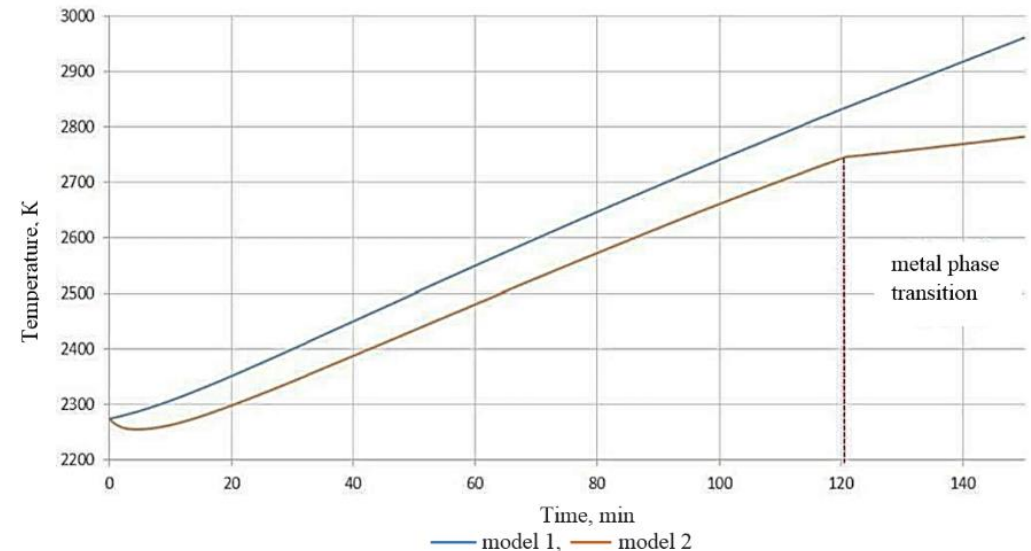

Fig.3. Change in the average temperature of the melt in different models.

Research on this work will be carried out on the LAVA-B experimental facility, created at the IAE NNC RK. This facility is used to study the processes accompanying a severe accident in a light water power reactor [26]. The facility allows melting up to $60 \mathrm{~kg}$ of a prototype mixture of LWR core materials by induction melting in a "hot crucible" followed by pouring the melt into the experimental section. To date, as part of the work at the LAVA-B facility, several research programs have been carried out:

- Experimental study of the interaction between fuel and coolant (FCI series) [27];

- Experimental study of the interaction between fuel and residual water inside reactor vessel (LHI series)[27];

- Studies of the interaction between core melt and concrete (MCCI)[27];

- Experimental study of non-stationary processes during retention of the corium in the reactor vessel while simulating residual heat release (INVECOR Project) [27];

- Experimental study of the interaction between corium and refractory materials (CORMIT Project) [28];

- Experimental studies to produce a model solidified corium, similar to the corium formed as a result of the accident at the Fukushima-1 Nuclear Power Plant (Fukushima Debris Project) [29].

- The experimental facility (Figure 4) includes two main functional blocks: an electric melting furnace (EMF) for preparing the prototype corium melt and a melt receiver (MR), which houses an experimental section for modeling the studied processes. 


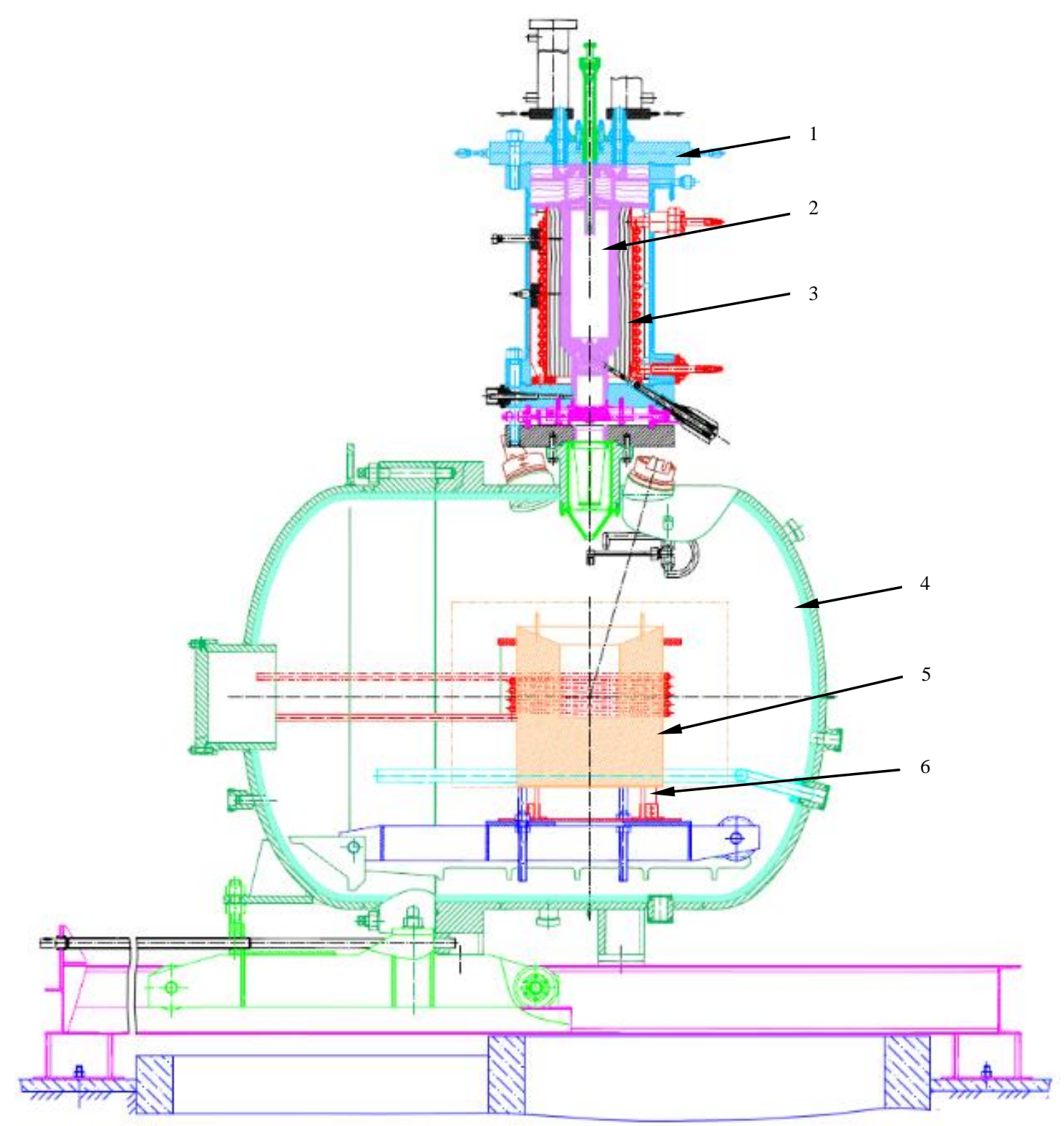

Fig.4. LAVA-B facility: 1 - EMF (electric melting furnace), 2 - graphite crucible, 3 - EMF inductor, 4 MR (melt receiver), 5 - MR inductor, 6 - concrete trap.

\section{Conclusion}

In the process of analyzing the results obtained in the course of modeling, conclusions were made about the influence of the presence of a lead layer on the process of interaction of the corium with the elements of the trap. This analysis allows us to conclude about the effectiveness of the presence of this layer, since it makes it possible to increase the heat removal from the corium for its heating and subsequent phase transition. Thus, in our opinion, one of the simplest alternative options for heat removal from the melt is use of a fluidized metal bed at the bottom of the trap during a period of time when supply of water to the melt is undesirable due to generation of hydrogen and a risk of steam explosion. It is necessary to experimentally determine and theoretically substantiate composition, thermal and physical properties of metal layer, which can create significant heat removal (more than 170-200 kJ/mol) from the corium during its boiling. The results of experimental studies will make it possible to conduct a substantiated analysis of the efficiency of a heat-resistant fluidized bed coating for an under-reactor melt trap designed to improve the safety of a nuclear power plant in the event of a severe accident with reactor core melting. 


\begin{abstract}
Acknowledgement
The work is carried out within the framework of the event «Development of nuclear energy in the Republic of Kazakhstan» for 2021-2023, in the budget program «Physics and technology of nuclear power», the topic «Investigation of the erosion properties of a composite material when interacting with corium».
\end{abstract}

\title{
REFERENCES
}

1 Gusarov V.V., et al. Physicochemical modeling and analysis of interaction between the core melt of a nuclear reactor and sacrificial material. Physics and chemistry of glass. 2005, Vol.31, No.1, pp.71-90.

2 Sidorov I.A. Melt localization device for NPP with WWER-1200. Proceeding of the 7th ISTC "Ensuring the safety of NPP with WWER", Podolsk, May 17-20, 2011, 13 p.

3 Sehgal B.R., et al. Melt-Structure-Water Interactions During Severe Accident in LWRs. NPSD, Royal Institute of Technology, Annual Report, Sweden, Nov. 2000, 147 p.

4 Stolyarevsky A. Does the trap save? Atomic strategy XXI, 2014, No.89, pp.16-18.

5 Sidorov A.S., Rogov M.F., Novak V.P., et al. Proceeding of the Conf. "Safety Issues of NPP with WWER", St. Petersburg, 2000, Vol.1, pp. $37-66$.

6 Kukhtevich I.V., Bezlepkin V.V., Khabensky V.B., et al. Proceeding of the conf. "Safety Issues of NPP with WWER”, St. Petersburg, 2000, Vol.1, pp. $23-36$.

7 Gusarov V.V., Khabensky V.B., Beshta S.V., et al. Proceeding of the conf. "Safety Issues of NPP with WWER", St. Petersburg, 2000, Vol.1, pp. $105-140$.

8 Gusarov V.V., Almyashev V.I., Beshta S.V., et al. Sacrificial materials for the safety system of nuclear power plants - a new class of functional materials. Heat Power Engineering, 2001, No.9, pp.22-24.

9 Gusarov V.V., AlmjashevV.I., Bechta S.V., et al. Proceeding of the $6^{\text {th }}$ Int. Workshop High-temperature. Super conductors and novelinorg. mater. engineering. Moscow, MSU, 2001, pp. $11-32$.

10 Almjashev V.I., Gusarov V.V., Bechta S.V., et al. Proceeding of the $6^{\text {th }}$ Int. Conf. on Intermolec. Interact. In Matter, Gdansk-Jelitkowo, 2001, 1 p.

11 Akopov F.A., et al. Nuclear reactor core melt trap. RF Patent RU 2169953 C2, 1999, 6 p.

12 Sidorov A.S., et al. Melt localization device. RF patent RU 2696612 C1, 2018, 10 p.

13 Gusarov V.V., et al. Oxide material of a nuclear reactor core melt trap. RF Patent RU 2192053, 2002,6 p.

14 Bezlepkin V.V., et al. Melt localization device. RF Patent RU 100327 U1, 2010, 6 p.

15 Gusarov V.V., et al. Method for producing ceramic materials for melting trap in the active zone of a nuclear reactor containing iron, aluminum and silicon dioxide. RF Patent RU 2206930 C1, 2003, 7 p.

16 Gusarov V.V., Khabensky V.B., Bechta S.V., et al. Oxide material for a molten core catcher of a nuclear reactor. PCT patent WO 02/080188, Nov. 21, 2002, 10 p.

17 Gusarov V.V., Khabensky V.B., Bechta S.V., et al. Oxide material for a molten-core catcher of a nuclear reactor. PCT patent WO 03/032325, Apr. 17, 2003, 10 p.

18 Mozhzherin V.A., SakulinV.Ya., Migal V.P., et al. Charge and oxide sacrificial material for a device for localizing a melt in the core of a nuclear reactor. RF Patent RU 2559294 C1, 2014, 9 p.

19 Nedorezov A.B., Sidorov A.S. Localization and cooling system of the core melt of a water nuclear reactor. RF patent RU 2576516 C1, 2014, 13 p.

20 Granovsky V.S., Khabensky V.B., Vasilenko V.A., et al. Device for localizing the corium of a pressurized water-cooled nuclear reactor. RF Patent No. 0002696012, 2019, 9 p.

21 Gusarov V.V., Beshta S.V., Khabensky V.B., et al. Oxide material of melt trap in the core of a nuclear reactor. RF patent RU $2191436 \mathrm{C} 1,2001,5$ p.

22 Gusarov V.V., Almyashev V.I., Beshta S.V., et al. Sacrificial materials of the safety system of nuclear power plants - a new class of functional materials. Thermal Engineering. 2001, No.9, pp.22-24.

23 Kukhtevich I.V., et al. The concept of localization of corium melt at the out-of-vessel stage of a beyond design basis accident at NPP with WWER-1000. Thermal Engineering. 2001, No.9, pp.2-7.

24 SidorovA.S., Rogov M.F., Novak V.P., et al. Device for localization of the melt of the Tianwan NPP with WWER1000.Thermal Engineering. 2001, No.9, pp.8-13.

25 Sehgal B.R., et al. Assessment of reactor vessel integrity (ARVI). Nucl. Eng. and Des., 2003, pp. 23 - 53.

26 Broughton J. M., et al. A scenario of the TMI-2 accident. Nuclear Technology, 1989, Vol.87, pp. $34-53$.

27 Nazarbayev N.A., et al. Study of the processes of severe accidents in reactor facilities. Scientific, Technical and Engineering Work to Ensure the Safety of the Former Semipalatinsk Test Site, 2016, Vol. III, pp. 320 - 356.

28 Tomohisa Kurita, Isao Sakaki, Fumiyo Sakaki, et al. Test and evaluation plan for passive debris cooling system, ICNRP - 2013. Proc. of the $9^{\text {th }}$ Intern. Conf. "Nuclear and radiation physics", 2013, Almaty, pp. $19-29$.

29 Shohei Kawano, et al. Characterization of fuel debris by large-scale simulated debris examination for Fukushima Daiichi nuclear power station, Proceedings of the ICAPP 2017 - Fukui and Kyoto (Japan), pp. 1105 - 1110. 